\title{
Changes in the representation of body deformities of primary school students under the influence of a six- month program
}

\author{
- Elvira Nikšić ${ }^{1}, \oplus$ Edin Beganović ${ }^{2}, \oplus$ Marko Joksimović ${ }^{3}$
}

${ }^{1}$ Faculty of Educational Sciences, University of Sarajevo, Sarajevo, Bosnia and Herzegovina. ${ }^{2}$ Faculty of Sport and Physical Education, University of Sarajevo, Bosnia and Herzegovina. ${ }^{3}$ Football club National, Podgorica, Montenegro.

\begin{abstract}
Proper body posture should be at the very top, as this is the basic prerequisite of good health, normal growth, and development. The aim of this research was to determine significant differences between the initial and final measurements in the results of body deformities in students of classroom teaching. The study was conducted on a sample of 1105 students, aged $5-12$ years. Diagnosis of body posture was performed according to Napoleon Wolanski's criteria. Measuring instruments/tests were used to measure the curvature of the spine, and the check of the structure of the feet was performed by the method of plantography. By analyzing the posture variables of individual body parts of the sample studied, using descriptive statistics, it was determined that there was a statistically significant representation of physical deformities, as well as statistically significant differences between the initial and final measurements in the results of physical deformities of class teaching students. The analysis of the obtained results provided data showing that in the initial measurement 231 students of class teaching have chest deformities, 792 students have spinal deformities, 267 students have leg deformities and 671 students have foot deformities. In the final measurement, 123 class teaching students have chest deformities, 488 students have spinal deformities, 133 students have leg deformities and 439 students have foot deformities. Based on the research it can be concluded that the frequency of physical deformities can be significantly reduced by planned and continuous corrective procedures, i.e. by applying appropriate content in physical and health education classes.
\end{abstract}

Keywords. Body posture, class, deformities, physical education.

\section{Introduction}

With school attendance, poor posture and deformities occur in children. Due to school obligations, physical activity decreases, as children spend most of their time in an incorrect sitting position, improper standing, to which should be added the time spent at home: watching TV, using the computer, video games, solving homework, inadequate bed and pillow for sleeping, being overweight, followed with tight, uncomfortable and heavy footwear, heavy clothing that pushes down the shoulders, and carrying a heavy school bag. Physical deformities that occur in childhood and are not corrected in time remain a permanent handicap and significantly affect the whole life of the child (Beganović \& Bešović, 2012). Improper posture is essentially an initial stage of a certain deformity, such as spinal deformities (scoliosis, lordosis, and kyphosis). Chest deformities (bulged breasts, recessed breasts, straight breasts), hip deformities (poor development, half-dislocation, dislocation), lower extremity deformities ("O" legs, "X" legs, saber legs), foot deformities (straight, raised) (Nikšić et al., 2015). Kosinac \& Katić (1999) in their study, they examined the proper posture of the head, shoulders, shoulder blades, Lorenzo angle as well as the physiological curves in the thoracic and lumbar spine in boys and girls of 10-14 years. The results of their study indicate that there are significant irregularities in these body segments. Disorders of 
body posture of school children occupy an increasing share in health status, which is very devastating given the age of the children themselves, and that confirm research of Paušić (2005) which states that $28.4 \%$ of children have first-class chest irregularly developed in primary school, lowering of the foot is present in $47.3 \%$ of first-grade students, while in second grade this deformity is present in as many as $60.7 \%$. The percentage of postural disorders of young people varies greatly among different authors, and it depends on the specificity of the sample, age, environment, methodology used in the detection of disorders, etc. That confirms research Krsmanović (2007) who states that $53 \%$ of the respondents have poor posture, while some authors point out that even more than $70 \%$ of school children have some physical disorders and certain problems resulting from lack of movement (Ristić et al., 2002). Several authors dealt with researches of correct body posture (Živković et al., 2004; Živković \& Karaleić, 2006; Krsmanović \& Bigović, 2006; Krsmanović, 2007; Medojević et al., 2007; Milošević et al., 2008). The aim of this research was to determine significant differences between the initial and final measurements in the results of body deformities in students of classroom teaching.

\section{Methods}

The research includes the population of elementary school students from Kantona Sarajevo (Bosnia and Herzegovina). The sample consists of a total of 1105 students both sexes. The research was conducted in the physical education halls of all primary schools. The study was approved by the Ethics Committee of the Faculty of Teacher Education, the University of Sarajevo in accordance with the Declaration of Helsinki (World Medical Association, 2013). The study was supported by all parents, who gave their written consent. A program of 6 months was implemented in this sample of respondents. The program was implemented in the period (October, November, December, February, March, April), with which teachers/professors of classroom teaching worked, Table 1. Within the program, certain corrective exercises were applied to prevent and correct the above mentioned postural disorders in different initial positions of the body. Exercises for strengthening weakened muscles should be applied daily, even two to three times a day. Since this is difficult for these students at the beginning, it is necessary to apply the exercises continuously. Each month the volume of exercise was gradually increased according to the progress of the students, as can be seen in Table 1 .

Variables used to assess body posture are criteria of Napoleon Wolanski were applied to evaluate the interrelationships of 8 body segments by visual projection of marked points. Deviations are classified according to their magnitude and are evaluated by so-called negative points, whereby:

- 0 points - indicates no deviation

- 1 point - indicates a slight deviation

- 2 points - indicates an extreme deviation

- Measurement of lateral curvature of the spinal column (scoliosis, kyphosis, lordosis)

- Verification of foot structure by plantography (Thomsen method)

Measurement of spinal curvature with the help of technical aids: (altimeter, liner, rope with altimeter).

All data collected through the survey were processed by descriptive and comparative statistics. The statistical package for personal computers SPSS Statistic 20.0 has been used for data processing.

\section{Results}

Assessment of the posture of the chest, and according to the type of deformity, in the students of the class teaching, there were data showing that in the initial measurement, $79.1 \%$ of students had a normal chest. In $18.1 \%$ of students, the chest is recessed, while $1.4 \%$ of students have a flat chest and $1.4 \%$ of students have a bulging chest (chicken breasts). In the final measurement in $88.9 \%$ of 
students the chest was normal. In $9.1 \%$ of students, the chest is recessed, while $1.0 \%$ of students have a flat chest and $1.0 \%$ of students have a bulging chest (chicken breast) Figure 1. In Figure 2, 3, and 4, we can see that in the initial measurement cases with a higher degree of spinal deformity (with all three types of deformities) are more represented. On the other hand, no cases with a second degree of deformity were identified in the final measurement in all three forms of spinal deformity. In the initial measurement, $79.4 \%$ of students have good posture. $18.7 \%$ of students grade I scoliosis, and $1.9 \%$ of students have grade II scoliosis. In the final measurement, $85.5 \%$ of students good posture. $14.5 \%$ of students had grade I scoliosis, while extreme deviation, grade II scoliosis, was not present in Figure 2. In the initial measurement, $64.9 \%$ of students have good posture. $19.9 \%$ of students a deformity called lordosis, grade I, and $15.2 \%$ of students have grade II lordosis. In the final measurement, $80.6 \%$ of students have a good body posture. $19.4 \%$ of students have a deformity that it is called lordosis, grade I, while extreme deviation, grade II lordosis, was absent Figure 3, called kyphosis of I grade, while extreme deviation, grade II kyphosis, was not present Figure 4.

Table 2 shows that each of the Wilcoxon's Zexpressions is statistically significant at a level far below $1 \%$. This means that there has been a significant decrease in the degree of each of these forms of spinal deformity in the final measurement, relative to the initial measurement.

Table 1

Corrective exercise program.

\begin{tabular}{lcccccc}
\hline Corrective program/Month & October & November & December & February & March & April \\
\hline Chest & $* * *$ & $* * * *$ & $* * * * *$ & $* * * *$ & $* * * * *$ & $* * * * *$ \\
Scoliosis & $* * *$ & $* * * *$ & $* * * *$ & $* * * *$ & $* * * * *$ & $* * * * *$ \\
Lordosis & $* * *$ & $* * * *$ & $* * * * *$ & $* * * *$ & $* * * * *$ & $* * * * *$ \\
Kyphosis & $* * *$ & $* * * *$ & $* * * * *$ & $* * * *$ & $* * * * *$ & $* * * * * *$ \\
Legs & $* * *$ & $* * * *$ & $* * * * *$ & $* * * *$ & $* * * * *$ & $* * * * * *$ \\
Foot & $* * *$ & $* * * *$ & $* * * * *$ & $* * * *$ & $* * * * *$ & $* * * * * *$ \\
\hline
\end{tabular}

Legend: * - Implementation of the programme contents by week.

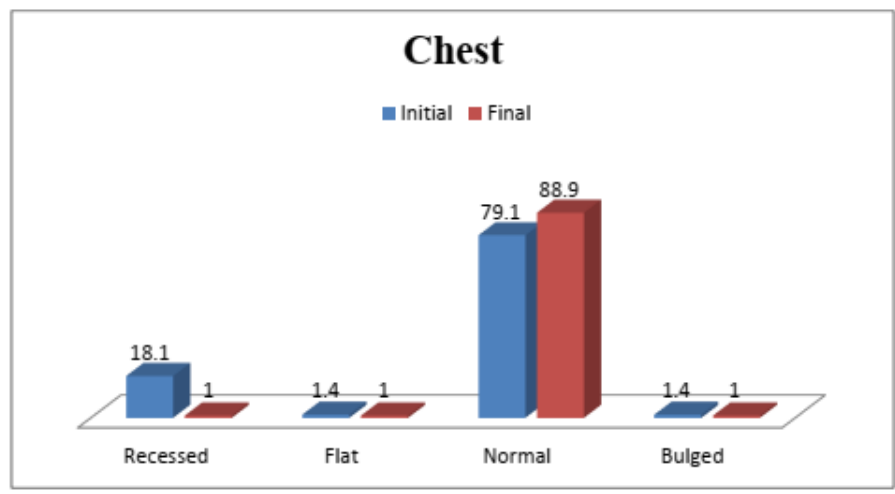

Figure 1. Chest posture in initial and final measurements.

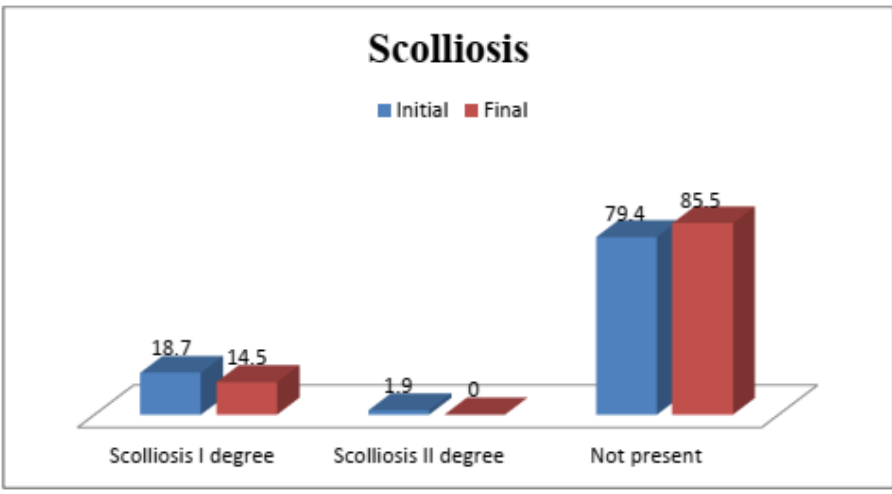

Figure 2. Scoliosis in initial and final measurements. 


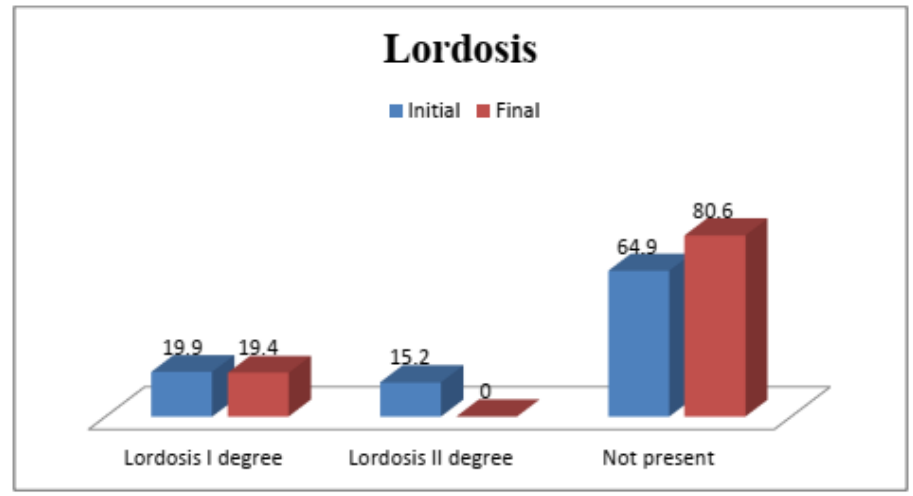

Figure 3. Lordosis in initial and final measurements.

Table 2

Wilcoxon's test.

\begin{tabular}{lcc}
\hline Body part & Z-value & $\mathrm{p}$ \\
\hline Kyphosis & -9.503 & $0.00^{* *}$ \\
Scoliosis & -9.037 & $0.00^{* *}$ \\
Lordosis & -18.075 & $0.00^{* *}$ \\
\hline
\end{tabular}

In the initial measurement of leg deformity of $75.8 \%$ of students had a normal posture. $11.4 \%$ of students have grade I X-legs, $0.3 \%$ of students have grade II X-legs, while $10.4 \%$ of students have O-legs, and $2.1 \%$ of students have saber legs. In the final measurement in $88.0 \%$ of students, the posture was normal. $5.2 \%$ of students have grade I X-legs, $5.1 \%$ of students have O-legs, and $1.7 \%$ of students have saber legs, while grade II X legs were not represented in the final measurement Figure 5. In the initial measurement of $39.3 \%$ of students had a well-formed foot. It is estimated by measuring footprint. (15.3\%) students have a flat foot I degree. $15.8 \%$ of students have a flat foot II degree, while $7.2 \%$ of students have a raised foot I degree and $22.4 \%$ of students have a raised foot II degree. In the final measurement, $60.3 \%$ of students have a well-formed foot. $21.0 \%$ of students have a flat foot I degrees, $0.3 \%$ of students have a raised foot I degrees, and $18.5 \%$ of students have a raised foot grade II, while a flat foot grade II is not represented in the final measurement Figure 6.

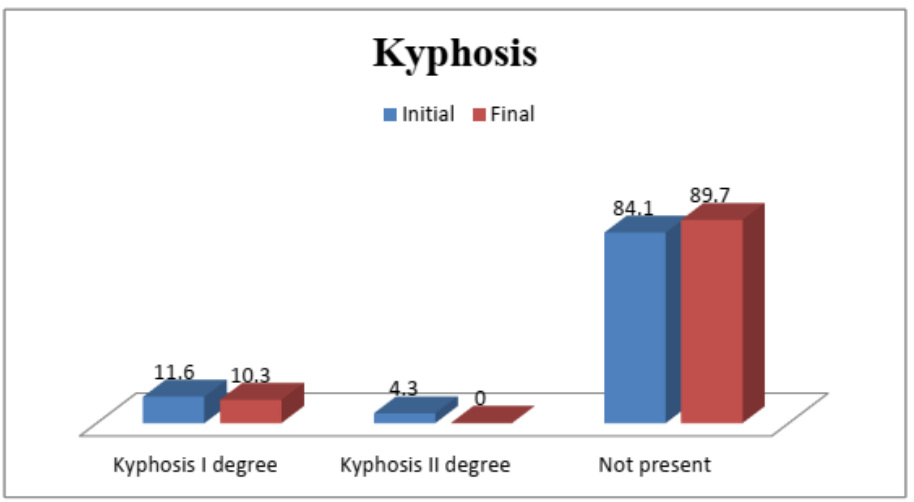

Figure 4. Kyphosis in initial and final measurements.

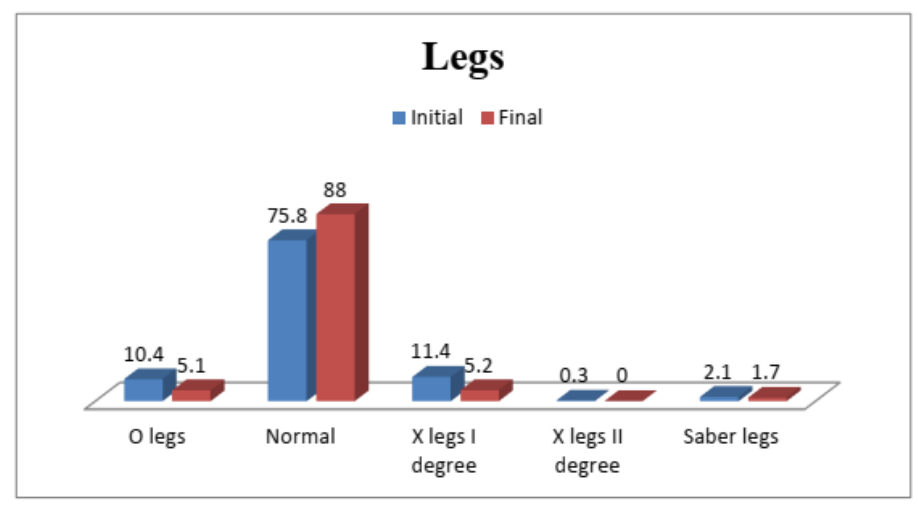

Figure 5. Legs posture ratings in initial and final measurements.

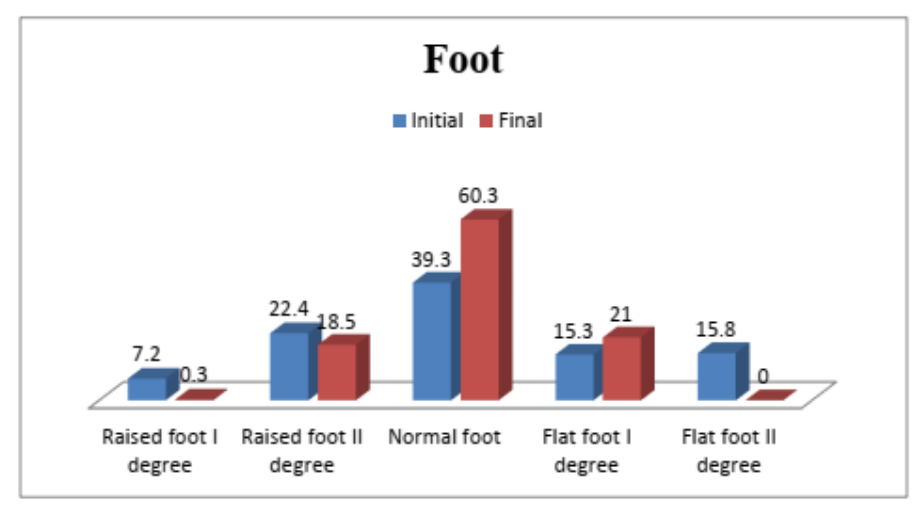

Figure 6. Foot posture ratings in initial and final measurements.

\section{Discussion}

The aim of this research was to determine significant differences between the initial and final measurements in the results of body deformities in students of classroom teaching. Analyzing the 
posture variables of individual body parts with the help of descriptive statistics, it was found that there is a statistically significant representation of physical deformities, as well as statistically significant differences between the initial and final measurements. Statistics show that about $4 \%$ of people have a deformity of the spinal column to any degree, and the reason is the so-called poor posture that is not remedied in time. Functional disturbances caused by improper posture are first reflected on the spinal column and later on other parts of the locomotor apparatus. The spine is the basic factor of upright posture and the weight carrier of all upper body parts. For this reason, it is often exposed to numerous deformities, which can affect the entire spinal column or only certain parts (Nikšić et al., 2019). Similar results they got Jovović \& Čanjak (2012) on a sample of younger adolescents of both sexes. They found that postural disorder was most prevalent wing blades are the most prevalent disorder in subjects, followed by postural disorders on the spinal column: (scoliosis, lordosis, and kyphosis). Lower extremity "O" disorders of the legs and flat feet also showed a high frequency. The presence of other deviations is lower, with the hollowed and bulging breasts being the least represented disorder in the cases studied, especially in girls. Functional disorders are by far the largest percentage of deviations, which can be successfully corrected by adequate physical treatment. The condition of the lower extremities is worse in girls than in young adolescents, as confirmed by the fact that the hollowed foot is more prevalent in female respondents (20.6\%). An exception is the flat foot, which is less prevalent in girls than in boys, with the greatest number of disorders related to the easier form of lowering of the arches $(\mathrm{Rf}=59.6 \%)$.

Spinal and foot deformities are most common among students in a class, as evidenced in the results obtained after the initial and final measurements. All deformities are less pronounced and represented in the final compared to the initial measurement. Based on the research, it can be concluded that the deformities can be significantly reduced through planned and continuous corrective procedures. It is necessary to develop an awareness of a healthy lifestyle that includes appropriate physical exercises, which have a preventative and corrective effect on the posture of young people. It is well known in science that youth is a period of life during which a properly managed exercise process can significantly influence development and change, i.e. reduction and suppression of improper posture. Physical deformities that occur in childhood and are not timely corrected remain a permanent handicap and significantly affect the entire life of the child. Only through the joint action and involvement of parents, educators and medical professionals, as well as all those who work with children, can the further deterioration of the postural status of young people be stopped and can the negative impact of the modern (sedentary) lifestyle be moderated.

\section{Acknowledgment}

The authors would like to thank every participant for his effort and time.

\section{Funding}

No external funding was received for this study.

\section{Declaration of Interest}

The authors report no conflict of interest.

\section{References}

Beganović, E., \& Bešović, M. (2012). Analysis of body posture in young school children in Sarajevo. Sportski Logos, 19, 25-33.

Jovović, V., \& Čanjak, R. (2012). Frequency and structure of postular disorders in young adolescent students in Montenegro. Proceedings Book - Zbornik Radova, 3 International Scientific Conference, Banja Luka, 113-119.

Kosinac, Z., \& Katić, R. (1999). The impact of some specific "school" measures of burden on orthostatic posture. Second International Scientific Conference Dubrovnik. Kinesiology for the 21st century (Proceedings). Zagreb: Faculty of Physical Culture, University of Zagreb, 141-143. 
Krsmanović, T. (2007). Postural disorders and how to prevent them. Journal of the Anthropological Society of Serbia, 42, 345-351.

Krsmanović, T., \& Bigović, M. (2006). Flexibility relations and deviation of the spinal column in the frontal plane. In: Bala G. (ed.), Anthropological status and physical activity of children and youth. Novi Sad: Faculty of Sports and Physical Education, 213-219.

Medojević, S., \& Jakšić, D. (2007). Differences in postural disorders between girls and boys of 7-15 years in the territory of Vojvodina. In: Bala G. (ed.), Anthropological status and physical activity of children, youth and adults. Novi Sad: Faculty of Sports and Physical Education. 4954.

Milošević, Z., \& Obradović, B. (2008). Postural status of children in Novi Sad preschools aged 7 years. Journal of the Anthropological Society of Serbia, 43, 301-309.

Nikšić, E., Mahmutović, I., \& Rašidagić, F. (2015). Analysis of posture by Napoleon Wolanski's criteria. Sport Science, 8(1), 85-93.

Nikšić, E., Rašidagić, F., Beganović, E., \& Zsolt, N. (2019). Examination of the differences in the representation of deformities of individual body parts in initial and final measuring. Sport Science, 12(1), 36-45.

Paušić, J. (2005). Assessments of body posture change in children aged seven to nine years. Master's thesis. Faculty of Kinesiology, University of Zagreb, Zagreb.

Ristić, V., Marković, V., \& Ljubić, M. (2002). Bone-joint deformities in elementary school students in Bojnik Municipality. Acta Medica Medianae, 41(3), 63-67.

Wolansky, N. (1975). Physical growth and development with monitoring of body posture. Teacher's Manual, Varšava.

World Medical Association. (2013). World Medical Association Declaration of Helsinki Ethical Principles for Medical Research Involving Human Subjects. JAMA, 310 (20).

Živković, D., \& Karaleić, S. (2006). Prisustvo lošeg držanja tela učenika mlađeg školskog uzrasta u zavisnosti od vrste sporta kojim se bave. Fizička kultura, 2, 186-188.

Živković, D., Milenković, S., \& Drobnjak, D. (2004). Stanje posturalnih poremećaja i telesnih deformiteta dece mlađeg školskog uzrasta u opštinama Zaječar, Kruševac i Čačak. Sport Mont, 2-3(2), 421-426. 